Research Article

\title{
Parental first concern according to age and type in children with Autism Spectrum Disorder
}

\author{
Dian Dwi Sary ${ }^{1}$, Irwanto ${ }^{2}$, Ahmad Suryawan ${ }^{3}$, Mira Irmawati ${ }^{4}$, Budi Utomo ${ }^{5}$ \\ 1) Department of Child Health, Faculty of Medicine, Universitas Airlangga \\ 2) Department of Child Health, Faculty of Medicine, Universitas Airlangga \\ 3) Department of Child Health, Faculty of Medicine, Universitas Airlangga \\ 4) Department of Child Health, Faculty of Medicine, Universitas Airlangga \\ 5) Faculty of Public Health, Universitas Airlangga
}

\section{A R T I C L E I N F O}

\begin{tabular}{ll}
\hline Submitted & $: 08^{\text {st }}$ August 2020 \\
Accepted & $: 03^{\text {st }}$ February 2021 \\
Published & $: 25^{\text {st }}$ July 2021
\end{tabular}

\section{Keywords:}

parent concern, autism, communication

\section{*Correspondence: \\ dian_dwisary@yahoo,com}

This is an Open acces article under the CC-BY-NC license

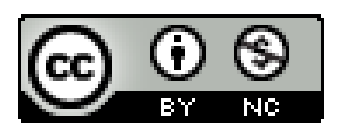

\begin{abstract}
Parents' developmental problems are a further diagnostic step for children with Autism Spectrum Disorder (ASD ). Research is needed to find a picture of the child's behavior complained of by parents. Investigations about parents' first concerns with ASD and comparisons of the same with children diagnosed with other developmental disorders are rare.We want to examine the type and age of parents' concerns in children with ASD and other developmental disorders. A cross-sectional study was conducted in Child Developmental Centre in Surabaya, Indonesia, from August 1 to December 30, 2019. T-test and chisquare tests were used to analyze differences in subject variables and types of concern. Most parents of both children diagnosed with ASD and non-ASD indicated first concern were in communication, social skill, and behavior problem. The average age of ASD children (54,77 months) is older than non-ASD children $(51,44$ months), but the average age of parents' first concern was younger for children with an ASD diagnosis (30,14 months) compare with non-ASD children $(31,39$ months). There is no specific difference type between parental concerns of children with ASD and non-ASD. The average age of first concern was significantly younger for children with an ASD diagnosis than other developmental disorders.
\end{abstract}




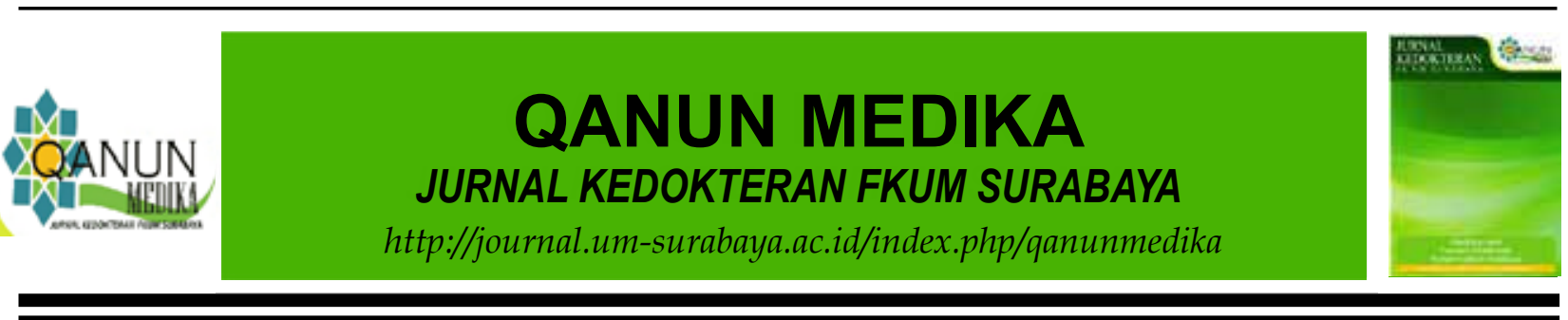

\section{INTRODUCTION}

Autism spectrum disorder (ASD) is a neurodevelopment disorder characterized by deficits in social communication and social interaction and limited or repetitive behaviors or interests (American Psychiatric Association, 2013). Globally, the number of autistic patients is expected to increase. The Center for Disease Control and Prevention (CDC) in 2014 said the prevalence rate had increased to 1 per 59 children (CDC,2018). One reason is the increase in public awareness and knowledge of parents about the symptoms of autism (Boyd et al., 2010).

The high number of children with ASD calls for a proper early diagnosis for early intervention to be done immediately, producing optimal outcomes in children with ASD (Kelley, Naigles, and Fein, 2010). A study by Barbaro and Dissanayake stated that clinicians were expected to be able to diagnose children with autism at an early age, even at the age of 2 years (Barbaro and Dissanayake, 2012) but several studies have shown that patients with ASD were diagnosed in the later age. Research in the United States reports the average age of diagnosed ASD children around four years (Zwaigenbaum et al., 2009). Another study in Lebanon says the average age to diagnose ASD is four years and seven months (AkouryDirani, Alameddin, and Salamun, 2013).

In contrast to the late diagnosis of ASD in children, parents' concerns about the possibility of developmental delays often appear earlier. Parents can recognize the disorder in children. This can be useful for the early identification of ASD, as mentioned in a study by BecerraCulqui. The study by Becerra-Culqui claims that the average age of children with ASD when parents first complained about the disorder was 31.5 months (Beccerra-Culqui et al., 2018). Another study by Richard said that the average age for complaints from parents to ASD children was 14 months. The study also stated that it is crucial for clinicians to pay attention to parental complaints as part of the diagnostic process (Richards, Mossey, and Robins, 2016).

In addition to the age when parents first raise their concern, studies on the types of concern itself also need to be conducted. Communication disorders become the most common initial complaint reported among parents of children with ASD (Beccerra-Culqui et al., 2018; Kozslowki et al., 2011; Zablotsky et al., 2017). Researchers also report other behaviors that also raised parents' concerns, such as limited/ recurring behavior disorder and socialization disorder (Richards, Mossey, and Robins, 2016; Kozslowki et al., 2011).

Parents' concern is the first indicator that a child has a developmental problem. It can be the first step in identifying children who need further screening or assessment. Research conducted to assess the first complaint in parents of children with ASD and compared with other developmental disorders has not been done much. Therefore, this study aims to evaluate and compare the initial complaints reported by parents of children with ASD and not ASD. The study also assessed whether there was an age difference between the onset of the first complaint between ASD and non-ASD children.

\section{METHOD}

\section{Study design}

A cross-sectional study was conducted in Child Developmental Centre in Surabaya, Indonesia, from August 1 to December 30, 2019.

\section{Participants}

One hundred and nineteen children who visited the Child Growth and Development Center in Surabaya from August 1 to December 31, 2019, were screened to participate in this study. Two 
hundred and one children were included, and they fulfill the following criteria: aged between 2 and 6 years with complaints of developmental disorders, parents or guardians agreed to participate in the study and sign informed consent. Children with blindness, deafness, Down syndrome, intellectual disabilities, and cerebral palsy were excluded from the study.

\section{Data collection}

The study sample was divided into two groups: The first group was for children who met the diagnostic criteria for ASD, and the second group was for children who have atypical development but did not meet the diagnostic criteria for ASD. The diagnosis of ASD was made by a Growth and Development pediatrician based on the criteria from the Diagnostic and Statistical Manual of Mental Disorder, Fifth Edition (DSM-5) (American Psychiatric Association,2013). Parents of these children would then fill a socio-demographic data and a questionnaire on the age at which the complaints first appear and the types of complaints.

\section{Ethics}

This research was approved by Ethics Committee Universitas Airlangga Institutional Review Board (170/EC/KEPK/FKUS/2019).

\section{Material}

Parents' responses on concern were categorized into five items, as adapted from research by Hess (Hess and Landa, 2011). Responses are categorized into the following items: Communication (including speech, verbal communication, and non-verbal communication), motor (including fine motor and gross motor), socialization, behavior/ temperament (including stereotyped/repetitive behaviors, and interests; challenging behavior, for example, aggression; temperamental characteristics such as stubbornness), and sensory (including sensory defensiveness or sensory seeking). All respondents' answers were recorded. If parents complain about more than one problem, every complaint would be recorded according to these categories. The percentage of complaints is calculated both for ASD and non-ASD.

American Academy of Pediatrics (AAP) (2020) stated that the diagnosis of ASD must be established according to DSM-5 criteria (Hyman et al., 2020). In the DSM-5, core symptoms were divided into two domains social communication and social interaction and restrictive, repetitive patterns of behaviors). To meet diagnostic criteria for ASD by using the DSM-5, all 3 symptoms of social, affective difference need to be present in addition to 2 of 4 symptoms related to restrictive and repetitive behaviors. The DSM-5 notes that a diagnosis may be made at older ages, when the social or school environment demands may result in functional impairment (American Psychiatric Association, 2013).

\section{Data analysis}

T-test and chi-square test were used to analyses differences in subject variable characteristics and types of complaints of research subjects using IBM SPSS Statistics for Windows, version 21 (IBM Corp., Armonk, N.Y., USA

\section{RESULT}

The demographic data for the two groups are present in Table 1. There were no significant differences between the ASD and non-ASD groups in age, sex, order of children and number of siblings, and age and education level of parents.

There were no significant differences between the ASD and non-ASD groups for the parents' first concern about their child's development. The average age when parents first raise their concern was 30.14 months (range $=12-60$ months) for children with ASD. This is earlier compared to the non-ASD group, which has an average of 31.39 months (range 10-72 months). 
Table 1. Demographic for subjects and each diagnostic group

\begin{tabular}{|c|c|c|c|}
\hline Variable & $\begin{array}{l}\text { ASD } \\
n=66\end{array}$ & $\begin{array}{l}\text { Not ASD } \\
n=135\end{array}$ & \\
\hline \multicolumn{4}{|l|}{ Child } \\
\hline \multicolumn{4}{|l|}{ Gender, n (\%) } \\
\hline - Male & $51(77,27)$ & $100(74,07)$ & 0,75 \\
\hline - Female & $15(22,73)$ & $35(25,93)$ & \\
\hline \multicolumn{4}{|l|}{ age (month) } \\
\hline mean $(\mathrm{sb})$ & $54,77(14,16)$ & $51,41(14,18)$ & 0,13 \\
\hline median (min-max) & $57(25-72)$ & $52(24-72)$ & \\
\hline \multicolumn{4}{|l|}{${ }^{\mathrm{a} A g e}$ of concern (month) } \\
\hline mean $(\mathrm{sb})$ & $30,14(12,34)$ & $31,39(13,25)$ & 0,49 \\
\hline median (min-max) & $24(12-60)$ & $27(10-72)$ & \\
\hline \multicolumn{4}{|l|}{ Birth order, n (\%) } \\
\hline - First & $32(48,48)$ & $66(48,88)$ & 0,65 \\
\hline - Second & $19(28,79)$ & $45(33,33)$ & \\
\hline - $\quad$ Third or more & $15(22,73)$ & $24(17,79)$ & \\
\hline \multicolumn{4}{|l|}{ Number of siblings, $\mathrm{n}(\%)$} \\
\hline - None & $27(40,91)$ & $56(41,48)$ & 0,57 \\
\hline - One & $22(33,33)$ & $53(39,26)$ & \\
\hline - Two & $14(21,21)$ & $20(14,81)$ & \\
\hline - $\quad$ Three or more & $3(4,55)$ & $6(4,45)$ & \\
\hline \multicolumn{4}{|l|}{ Mother } \\
\hline \multicolumn{4}{|l|}{ Age (year) } \\
\hline Mean (sb) & $35,02(5,17)$ & $33,54(5,80)$ & 0,81 \\
\hline Median (min-max) & $35(24-47)$ & $33(20-48)$ & \\
\hline \multicolumn{4}{|l|}{ Education, $\mathrm{n}(\%)$} \\
\hline - Low & $34(51,51)$ & $84(62,22)$ & 0,19 \\
\hline - High & $32(48,49)$ & $52(37,38)$ & \\
\hline \multicolumn{4}{|l|}{ Father } \\
\hline \multicolumn{4}{|l|}{${ }^{\mathrm{a} A g e}$ (year) } \\
\hline mean $(\mathrm{sb})$ & $37,91(5,22)$ & $36,04(6,41)$ & 0,02 \\
\hline Median (min-max) & $38(26-48)$ & 35 )22-52) & \\
\hline \multicolumn{4}{|l|}{ Education } \\
\hline - $\quad$ Low & $33(50)$ & $69(51,11)$ & 1,00 \\
\hline - High & $33(50)$ & $66(48,89)$ & \\
\hline
\end{tabular}

Chi-square test, ${ }^{\mathrm{a}}$ Mann-Whitney test (data distribution is not normal)

Table 2. Percentage of concern by ASD and non-ASD parent groups.

\begin{tabular}{llll}
\hline Category & ASD n (\%) & Non-ASD n (\%) & $\mathbf{X}^{\mathbf{2}}$ \\
\hline Communication & $65(98,40 \%)$ & $102(75,55 \%)$ & 0,00 \\
Social skill & $45(68,18 \%)$ & $89(65,92)$ & 0,87 \\
Behavior/temperament & $29(43,93 \%)$ & $15(11,11 \%)$ & 0,00 \\
Sensory & $10(15,15 \%)$ & $3(2,22)$ & 0,00 \\
Motoric skill & $6(9,09 \%)$ & $7(5,18 \%)$ & 0,45 \\
\hline
\end{tabular}


Among the parents of children diagnosed with ASD, the first concerns reported were communication $(98.40 \%)$, socialskills $(68.18 \%)$, and behavior/temperament disorders (43.93\%). Concerns reported by parents of non-ASD children for the first time were communication (75.55\%), social skills (65.92\%), and behavior/ temperament disorders (11.11\%) (Table. 2). Parents of children with ASD were significantly more likely to report communication problems ( $p<0.001)$, behavior or temperament disorder $(p=0.001)$, and sensory problems $(p=0.001)$ compared to parents of non-ASD children.

\section{DISCUSSION}

The expression of parental concerns may be a clinician's first indicator that a child is experiencing developmental difficulties. Therefore, parental input can be essential in identifying children who need further screening or assessment for early diagnosis and intervention, as mentioned in a study by Richard (2016) (Richards, Mossey, and Robins, 2016). AAP also says parental concerns as an essential component of ASD screening (Hyman et al., 2020). However, despite the importance of parental concerns in early diagnosis and intervention of ASD, studies that compare parents' first concern between non-ASD children and ASD children are still limited.

The average age of concern for parents of ASD children found in this study is 30.14 months, which is relatively older than the findings in other studies done by Kozlowski (12.94 months), Richard (13.77 months), BecerraCulqui (32 months), and Zuckerman (30 months) (Kozslowki et al., 2011; Richards, Mossey, and Robins, 2016; Beccerra-Culqui et al., 2018; Zuckerman, Lindly, and Sinche, 2015). This difference occurs because previous studies use at-risk populations and are conducted on tertiary referral sites. This caused symptoms to be more prominent, thus more recognizable for parents (Beccerra-Culqui et al., 2018; Kozslowki et al., 2011). A study in China shows a similar average age, which is 3.1 years. This study also stated that the presence of negative stigma and lack of knowledge about ASD also caused parents to raise their concerns at a later age (Qian, Reichle, and Bogenschutz, 2012). The same condition is also present in this study, where parents have low awareness of ASD symptoms and assume that the symptoms will decrease and disappear as the child develop. This caused parents to report concerns about their children's behavior around the age of 3 years old.

This study also reports that parents of nonASD children first reported their concern at an average age of 31.39 months, longer than parents of children with ASD. This aligns with the results of studies conducted by Zuckerman and Kozloswki which also found that parents of non-ASD children reported concerns about their child's development several months later than parents of ASD children (Zuckerman, Lindly, and Sinche, 2015; Kozslowki et al., 2011). However, this finding contradicts the AAP statement that early signs are difficult for parents to detect if ASD symptoms are mild and the child's cognitive abilities are average or above average (Hyman et al., 2020).

It has been suggested that mothers with old age and a history of infertility tend to dismiss their children's late developmental signs, resulting in an older age of concern (Chawarska et al., 2007). This does not appear to be the case. Results of this study showed that age, mother's education, number of siblings, and birth order were not contributing factors in the age of concern in children with ASD. Studies by Chawarska (2007) and Herlihy (2015) further suggested that birth order and the number of siblings can be significant if the previous children have ASD (Chawarska et al., 2007; Herlily et al., 2015). However, this study cannot come to a similar conclusion because these supporting data were not collected. 


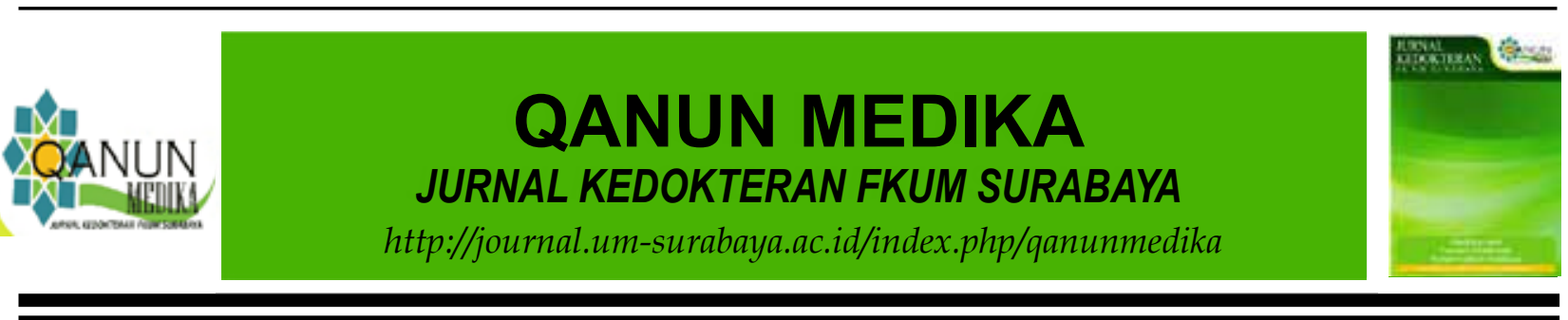

The results of this study showed that the first concern for most parents in both groups is communication problems, followed by social skills, behavior/temperament problems, sensory and motor skills. These results indicate that the initial complaints reported by parents of children with ASD care not necessarily relate to symptoms of autism. This finding consists of the results of previous studies on similar subjects (Richards, Mossey, and Robins, 2016; Kozslowki et al., 2011; Hess and Landa, 2011; Coonrod and Stone, 2004).

In this study, we found that communication problems are the most common complaint seen in both groups. Although communication problem is one of the core aspects of the DSM5 criteria to diagnose autism, it is not exclusive to autism disorder only and can indicate other global development delays (Richards, Mossey, and Robins, 2016; Kozslowki et al., 2011). Parents in the children with ASD group almost all complained about communication problems, compared to $75.5 \%$ of parents of non-ASD children. This result shows that communication problems often occur in children who receive various diagnoses of developmental disorders.

Another most common parental concern we found in this study concerns the ability to make social interactions. There is no significant difference in complaints of social interaction between parents of children with ASD and parents of non-ASD children. This study also finds that parental concern about socialization skills arises when the child is around three years of age. A possible explanation for the lack of significant difference between these groups is that these symptoms are not always realized by parents, especially those who have no experience of caring for older siblings or have compensatory mechanisms for children (Coonrod and Stone, 2004; Twymana et al., 2009; Karp et al., 2017). Socialization skills are also usually acquired in older children when they start to interact with their peers, which might explain why the parental concern of socialization skill might arise later, despite findings by Twyman in 2009 about how socialization impairment can be detected in children as young as 18 months old (BeccerraCulqui et al., 2018; Hess and Landa, 2011; Twymana et al., 2009).

The next parental concern that arises in this study is behavior/temperament issues reported by parents when the child is around 3 years old or as the problems arise. Parents tend to dismiss the behavioral problems to realize the concern when the normal developmental phase has passed. It is very hard for parents to recognize ASD-specific behavior in the early years since it usually appears when they are around 2 years old. A study by Sacrey in 2015 found that behavioral issues tend to arise when the child is around 2-3 years old (Herlily et al., 2015; Canu et al., 2020; Sacrey et al., 2015). This condition can be exacerbated by issues caused by other behavioral disorders like ADHD (Zablotsky, Bramlett, and Blumberg, 2017).

One of the least-reported parental concerns in this study is only focusing on certain objects or unusual responses to touch, taste, smell, and/ or sound, which is a new criterion to diagnose ASD based on DSM-5 (American Psychiatric Association, 2013). This symptom will often appear in children with ASD, which is following with the result of this study that finding this symptom can differentiate between children with ASD and non-ASD children.

There has been no correlation between parental concern on motor function and ASD. Previous studies have stated that motor disturbance in children with ASD may happen early, even as early as 18 months (Sacrey et al., 2015; Lee and Bo, 2015). There is a possibility that in this study, parents did not raise a concern about the motor function of their children until these children have passed the normal developmental phase. 


\section{CONCLUSION}

This study found no specific difference type between parental concerns of children with ASD and non-ASD. The main concern of parents of both groups is communication problems, socialization skills, and behavioral issues. Parents of children with ASD would first report concerns at an early age compared to parents of children with no ASD diagnosis.

\section{REFERENCE}

Akoury-Dirani L, Alameddin M, dan Salamun M. (2013). Validation of the Lebanese childhood autism rating scale-second edition-standard version. Research in Autism Spectrum Disorder, 7(9),10971103.

American Psychiatric Association. (2013). Diagnostic and statistical manual of mental disorder $5^{\text {th }}$ ed. Washington, DC: American Psychiatric Association Publishing.

Barbaro J and Dissanayake C. (2012). Early markers of autism spectrum disorders in infants and toddlers prospectively identified in the social attention and communication study. Autism, 17(1), 6468 .

Boyd BA, Odom S L, Humphreys B P, and Sam AM. (2010). Infants and toddlers with autism spectrum disorder: Early identification and early intervention. Journal of Early Intervention, 32(2), 7598.

Becerra-Culqui TA, Lynch FL, Owen-Smith AA, Spitzer J, and Croen LA. (2018). Parental first concerns and timing of autism spectrum disorder diagnosis. Journal of Autism and Developmental Disorders, 48(10), 3367-3376.
Canu D, Van der Paelt S, Canal-Bedia R, Posada M, Vanvuchelen M and Roeyers

H. (2020). Early non-social behavioural indicators of autism spectrum disorder (ASD) in siblings at elevated likelihood for ASD: a systematic review. European Child and Adolescent Psychiatry, https:// doi.org/10.1007/s00787-020-01487-7.

Centers for Disease Control and Prevention. (2018). Prevalence of autism spectrum disorder among children aged 8 years Autism and developmental disabilities monitoring network, 11 Sites, United States, 2014, MMWR Surveill Summ, 67(6), 1-23.

Chawarska K, Paul R, Klin A, Hannigen S, Dichtel LE, and Volkmar F. (2007). Parental recognition of developmental problems in toddlers with autism spectrum disorders. Journal of Autism and Developmental Disorder, 37(1), 6272.

Coonrod EE and Stone WL. (2004). Early concerns of parents of children with autistic and nonautistic disorders. Infant and Young Children, 17(3), 258-268.

Herlihy L, Knoch K, Vibert B, and Fein D. (2015). Parents' first concerns about toddlers with autism spectrum disorder: Effect of sibling status. Autism, 19(1), 2028.

Hess CR and Landa RJ. (2011). Predictive and concurrent validity of parent concern about young children at risk for autism. Journal of Autism and Developmental Disorders, 42(4), 575-584. 

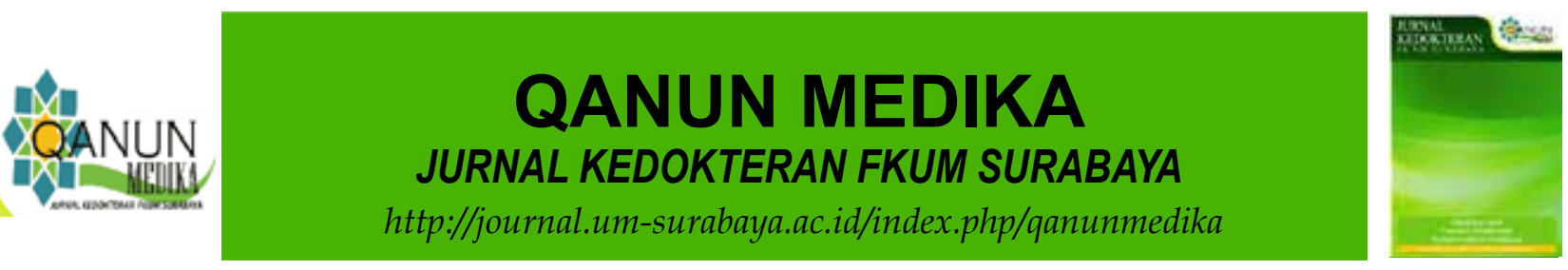

Hyman SL, Levy SE, Myers SM, and Council on Children with Disabilities, Section on Developmental and Behavioral Pediatrics. (2020). Identification, evaluation, and management of children with autism spectrum disorder. Pediatrics, 145(1), e20193447.

Karp EA, Ibañez LV, Warren Z, and Stone WL. (2017). Brief report: what drives parental concerns about their 18-montholds at familial risk for autism spectrum disorder? Journal of Autism and Developmental Disorder, 47(5), 15351541.

Kelley E, Naigles L, and Fein D. (2010). An in-depth examination of optimal outcome children with a history of autism spectrum disorders. Research in Autism Spectrum Disorder, 4(3), 526-538.

Kozlowski AM, Matson JL, Horovitz M, Worley JA, and Neal D. (2011). Parents' first concerns of their child's development in toddlers with autism spectrum disorders. Developmental Neurorehabilitation, 14(27), 72-78.

Lee CM and Bo J. (2015). Motor functioning in children with autism spectrum disorder. Acta Psychopathologica, 1(2), 13

Qian X, Reichle J, and Bogenschutz M. (2012). Chinese parents' perceptions of early development of their children diagnosed with autism spectrum disorders. Journal of Comparative Family Studies, 43(6), 903-913.

Richards M, Mossey J, and Robins DL. (2016). Parents' concerns as they relate to their child's development and later diagnosis of autism spectrum disorder. Journal of Developmental \& Behavioral Pediatrics, 37(7), 532-540.

Sacrey LAR, Zwaigenbaum L, Bryson S, Brian J, Smith IM, Roberts W, Szatmari
P, Roncadin C, Garon N, Novak C, Vaillancourt T, McCormick T, MacKinnon B, Jilderda S, and Armstrong V. (2015). Can parents' concerns predict autism spectrum disorder? a prospective study of high-risk siblings from 6 to 36 months of age. Journal of the American Academy of Child and Adolescent_Psychiatry, 54(6), 470-478.

Twymana KA, Maxim RA, LeetTL, and Ultmann MH. (2009). Parents' developmental concerns and age variance at diagnosis of children with autism spectrum disorder. Research in Autism Spectrum Disorders, 3(2), 489-495.

Zablotsky B, Bramlett MD, and Blumberg SJ. (2017). The Co-occurrence of autism spectrum disorder in children with ADHD. Journal of Attention Disorders, 24(1), 94103.

Zablotsky B, Colpe LJ, Pringle BA, Kogan MD, Rice C, and Blumberg SJ. (2017). Age of parental concern, diagnosis, and service initiation among children with autism spectrum disorder. American Journal on Intellectual and Developmental Disabilities, 122(1), 49-61.

Zuckerman KE, Lindly OJ, and Sinche BK. (2015). Parental concerns, provider response, and timeliness of autism spectrum disorder diagnosis. Journal of Pediatrics, 166(6), 1431-9. e1.

Zwaigenbaum L, Bryson S, Lord C, , Rogers S, Carter A, Carver L, Chawarska K, Constantino J, Dawson G, Dobkins K, Fein $\mathrm{D}$, Iverson J, Klin A, Landa R, Messinger D, Ozonoff S, Sigman M, Stone W, TagerFlusberg H, and Yirmiya N. (2009). Clinical assessment and management of toddlers with suspected autism spectrum disorder: insights from studies of highrisk infants. Pediatrics, 123(5), 1383-91. 